\title{
Synthesis of Cu-Al-Zn-O nanocomposite: effect of annealing on the physical properties
}

\author{
LAYA DEJAM ${ }^{1, *}$, SEYED MOHAMMAD ELAHI ${ }^{1}$, MAJID MOJTAHEDZADE LARIJANI ${ }^{2}$ and \\ YOUSEF SEYED JALILI ${ }^{3}$ \\ ${ }^{1}$ Department of Physics, Science and Research Branch, Islamic Azad University, Tehran, Iran \\ ${ }^{2}$ Radiation Applications Research School, Nuclear Science and Technology Institute, Tehran, Iran \\ ${ }^{3}$ Nano-Optoelectronics Lab, Sheykh-Bahaee Research Complex, Tehran Science and Research Branch, \\ Islamic Azad University, Tehran, Iran
}

MS received 1 June 2015; accepted 10 August 2015

\begin{abstract}
We prepared Cu-Al-Zn-O (CAZO) nanocomposite thin films on quartz substrates by radio frequency (RF) magnetron sputtering method. The as-deposited CAZO film is amorphous in nature and annealing in air environment results in weak crystallization of the films and formation of $\mathrm{CuAlO}_{2}$ and $\mathrm{CAZO}$. The surface morphology of the films was studied with atomic force microscopy images, while Rutherford backscattering spectrometry (RBS) was used to characterize material properties. The optical bandgap of films was found to be 3-4.2 eV depending on the annealing temperature. The photoluminescence (PL) of the samples was measured at room temperature. Violet, blue and green spectra peaks were observed from the PL spectra of the four samples. The emission spectrum indicates the suitability of CAZO nanocomposite for gas sensor applications and technology.
\end{abstract}

Keywords. Cu-Al-Zn-O nanocomposite; RF magnetron sputtering; annealing; photoluminescence.

\section{Introduction}

Transparent conductive oxides (TCOs) are binary or ternary oxides of metals with high free carrier density, excellent electrical conductivity and high optical transmittance in the UVVIS-NIR spectrum. As intrinsic, stoichiometric TCOs do not exhibit high conductivity and transmittance, such characteristics can be obtained by using appropriate dopants; thus, producing oxides with a non-stoichiometric composition. ${ }^{1}$

A composite is a multiphase solid material. It is incorporated by two or more individual materials through physical or chemical methods, the property of composite materials is better than that of each original material to meet different requirements. ${ }^{2}$ Nanocomposite films that consist of small metal particles in the range of a few to several nanometres $(\mathrm{nm})$ embedded in metal oxides have attracted attention due to their many useful electronic and optical properties as a result of quantum size effects. ${ }^{3}$ These systems find useful applications in catalysis, photocatalysis, sensors and novel optoelectronic devices.

$\mathrm{ZnO}$ nanostructures display novel size-dependent effects, ${ }^{4}$ good electrical properties and high luminescence yields. ${ }^{5,6}$ $\mathrm{ZnO}$ thin films have the potential to be used as thin solar cells and field effect transistors. ${ }^{7,8}$ Zinc oxide is a direct bandgap $(\sim 3.37 \mathrm{eV})$ semiconductor material and has a stable

\footnotetext{
*Author for correspondence (layadejam@gmail.com; 1.dejam@srbiau.ac.ir)
}

wurtzite structure with the lattice spacing of $a=0.325$ and $c=0.521 \mathrm{~nm}$.

Aluminium oxide $\left(\mathrm{Al}_{2} \mathrm{O}_{3}\right)$ is one of the most versatile ceramic oxides and has been used in a wide range of applications as in electrical, engineering and biomedical areas, depending on its purity and crystallinity. Aluminium oxide is commercially produced from bauxite at low cost, but the purity and particle morphology are not suitable for many applications. ${ }^{9}$ However, copper oxide is a semiconductor with a bandgap of $1.4 \mathrm{eV}$, which absorbs strongly in a visible spectrum. ${ }^{10}$

$\mathrm{ZnO} / \mathrm{Al}, \mathrm{ZnO} / \mathrm{Cu}$ and nanocomposite films have been prepared by various deposition methods ${ }^{11,12}$ but among these, reactive sputtering is the most widely used method. ${ }^{13,14}$ However, the use of functional matrix materials like $\mathrm{ZnO}$, $\mathrm{MgO}, \mathrm{CuO}$ and $\mathrm{Al}_{2} \mathrm{O}_{3}$ for the preparation of nanocomposites is relatively recent. ${ }^{15,16}$ Recently, ordering of metal atoms in semiconductor compounds is attracting more interest because they are not thermodynamically stable under bulk growth conditions. Furthermore, it is accompanied by change in the bandgap even for fixed composition. ${ }^{3}$

The properties of films generally change at high temperatures and also in different atmospheres. Therefore, the annealing is an important process to modify and/or improve the optical and electrical properties of the films. ${ }^{17}$

In this study our aim is to study $\mathrm{Cu}-\mathrm{Al}-\mathrm{Zn}-\mathrm{O}$ (CAZO) nanocomposite thin films deposited by RF magnetron sputtering. The as-deposited thin films represent inferior physical properties due to the amorphous nature of their structures; 
hence, it is highly favourable to study the effect of annealing on the structural, morphological and optical properties of CAZO thin film structures. Although many research works have been based on $\mathrm{Cu}: \mathrm{ZnO}$ and $\mathrm{Al}: \mathrm{ZnO}$ composite thin films, to the best of our knowledge there are very few reports on the properties of CAZO thin films.

\section{Experimental}

The CAZO thin films have been prepared by RF-magnetron co-sputtering on to quartz substrates. The sputtering target was constructed from zinc oxides, aluminium oxides and copper oxides powder of $99.9 \%$ purity. The $\mathrm{ZnO} 40 \%$, $\mathrm{Al}_{2} \mathrm{O}_{3} 55 \%$ and $\mathrm{CuO} 5 \%$ (weight ratios) powders were mixed using a fast mill. The mixed powder was then pressed under $120 \mathrm{MPa}$ at room temperature in air. Before depositing the films, the surface of CAZO target surfaces were cleaned by pre-sputtering under the film deposition conditions for 10 min. Quartz substrates $\left(10 \mathrm{~mm} \times 20 \mathrm{~mm}^{2}\right)$ were cleaned by ultrasonics in acetone and alcohol. The thin films were grown at room temperature inside a deposition chamber evacuated to a base pressure of $5 \times 10^{-5}$ mbar. The sputtering time and working gas pressure were fixed at $30 \mathrm{~s}$ and $1 \times 10^{-2}$ mbar, respectively. During the deposition process, pure argon (purity of 99.999\%) was used as the sputtering gas. Deposition was carried out at constant RF power regime of $400 \mathrm{~W}$. After deposition, the films were post-annealed at 300, 600 and $900^{\circ} \mathrm{C}$ temperatures for $1 \mathrm{~h}$ in air ambient. To obtain a desired annealing temperature, the furnace was steeply raised up from room temperature with the rate of $100^{\circ} \mathrm{C} \mathrm{h}^{-1}$. The samples were then slowly cooled to room temperature. The thickness of films was measured by a DEKTAK3 profilmeter and found to be $100 \pm 10 \mathrm{~nm}$.

X-ray diffraction (XRD) was performed on STOE-XRD diffractometer using $\mathrm{Cu}-\mathrm{K}_{\alpha}$ line $(l=0.15406 \mathrm{~nm})$. Atomic force microscopy (AFM) micrographs were obtained using Auto probe CP, from Park Scientific Instruments, in contact mode. The optical properties of thin films were examined by a Varian Cary-500 spectrophotometer and to characterize the luminescence properties of films the room temperature photoluminescence of the samples was measured using a Cary Eclipse spectrometer equipped with a xenon lamp. The compositional depth profile was studied by Rutherford Backscattering spectrometry (RBS) using a $2.0 \mathrm{MeV} \mathrm{He}{ }^{+}$ion beam. The recorded RBS spectra were processed by the SIMNRA simulation computer program.

\section{Results and discussion}

\subsection{Structure analysis of CAZO nanocomposite thin films}

Figure 1a and $\mathrm{b}$ shows the XRD patterns of CAZO target and the as-deposited film and post-annealed films at different temperatures, respectively. As-deposited CAZO thin film does not illustrate any characteristic sharp diffraction line, thus indicating an amorphous structure. This behaviour could be due to the short sputtering time and also substrate cooling during the deposition process, which hinders the required atomic displacement and grain boundary movement necessary for crystallization. ${ }^{13}$ As illustrated in figure $1 \mathrm{~b}$, at annealing temperature of $300^{\circ} \mathrm{C}$ some weak but notable peaks that could be interpreted as evidence for crystallinity of the films appear at 41.68 and 48.22 degrees. These peaks correspond to $\mathrm{CuAlO}_{2}$ (104) and $\mathrm{CuAlO}_{2}$ (009), respectively (01-075-2359 PDF card). By increasing the annealing temperatures from 300 to $600^{\circ} \mathrm{C}$, those peaks get weaker and at $900^{\circ} \mathrm{C}$ seem to disappear completely. On the other hand, by increasing the annealing temperature to $900^{\circ} \mathrm{C}$ new peaks appear at 31.6, 34.62 and 36.20 degrees, which are the characteristic peaks of hexagonal wurtzite-type $\mathrm{ZnO}$ structure. All diffraction results are in agreement with the JCPDS 001079-0207 card for ZnO. The weakness of these peaks with respect to pure $\mathrm{ZnO}$ ( $\mathrm{ZnO}$ thin film has sharp peaks at 31.6, 34.38 and 36.18 degrees) thin films may be due to the diffusion of $\mathrm{Al}$ and $\mathrm{Cu}$ atoms into the $\mathrm{ZnO}$ thin film structure. We guess thus a shift to higher angle position compared with pure $\mathrm{ZnO}$, indicating a decrease in the lattice constants. On the other hand, doping and high annealing temperature leads to change in the atomic environment and disorder of the $\mathrm{ZnO}$ crystal which is caused by the decrease in the crystallinity of $\mathrm{ZnO}$. Also, the same trend was observed in $\mathrm{Cu}^{-18}$ and Al-doped $\mathrm{ZnO}$ films. ${ }^{19}$

\subsection{Surface morphology and RBS analysis}

Figure 2a-d indicates surface morphology of CAZO thin films that were determined over a $2 \times 2 \mu \mathrm{m}^{2}$ area using AFM analysis. The root mean square (RMS) roughness were changed from 2 to $4 \mathrm{~nm}$. The as-deposited CAZO thin films is a bit porous, hence the films become relatively compact and their average particle size was increased after annealing at $300^{\circ} \mathrm{C}$. With further increasing the annealing temperature at $600^{\circ} \mathrm{C}$, the thin films further agglomerate but still hold a small amount of pores structure. The annealed sample at $900^{\circ} \mathrm{C}$ is denser and contains fewer pores. Thus, annealing treatment is changing the structural properties of CAZO nanocomposite thin films, but according to our observation the annealing treatment has no remarkable effect on the roughness and particle size of CAZO thin films.

Figure 3 illustrates a typical RBS spectrum of the CAZO thin films prepared at $300^{\circ} \mathrm{C}$ with the corresponding simulation curve obtained from the SIMNRA code. Film thicknesses were estimated using the RBS spectra at about $100 \pm$ $20 \mathrm{~nm}$.

According to figure 4, by increasing the annealing temperature, $\mathrm{Zn}$ and $\mathrm{Cu}$ peaks shift to lower energies, but the $\mathrm{Al}$ edge shifts to higher energies. These observations indicate the penetration of $\mathrm{Zn}, \mathrm{Cu}$ and $\mathrm{Al}$ atoms into each other. ${ }^{20}$ Also, further the XRD pattern of the samples at high annealing temperature confirms the reaction of $\mathrm{Al}, \mathrm{Zn}$ and $\mathrm{Cu}$ with oxygen. 


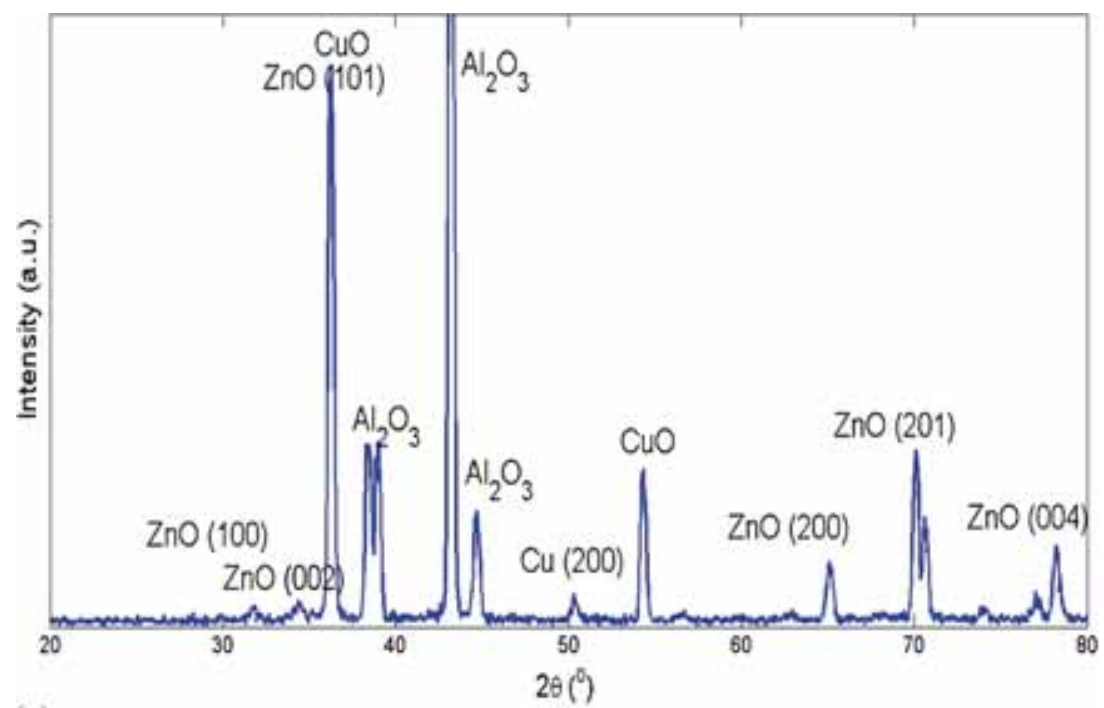

(a)

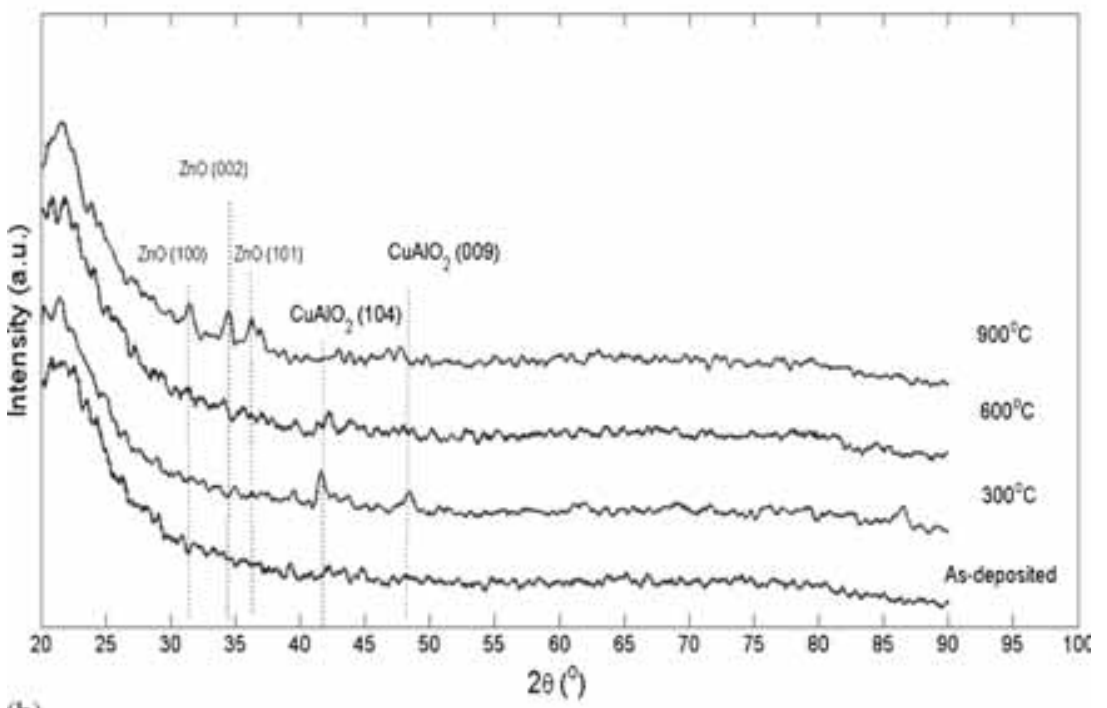

(b)

Figure 1. XRD patterns of (a) CAZO target and (b) CAZO nanocomposites of thin films.

Figure 4 illustrates an asymmetric band within the 1800$1900 \mathrm{keV}$ spectral range, which is attributed to the collective contribution of $\mathrm{Cu}$ and $\mathrm{Zn}$ atoms due to their adjacent atomic number and nearly overlapped distributions. ${ }^{21}$ Also, the band was deconvolved into two Gaussian-shaped components as plotted in figure $5 \mathrm{a}-\mathrm{c}$. By increasing the annealing temperature the separation of these two peaks gets more pronounced. This may be due to different thermal diffusivity of zinc and copper at high annealing temperature, where the value of thermal diffusivity of zinc and copper are $4.08 \times$ $10^{-5}$ and $1.11 \times 10^{-4} \mathrm{~m}^{2} \mathrm{~s}^{-1}, 22$ respectively. The higher thermal diffusivity of copper is an indication that the $\mathrm{Cu}$ atoms may contact the thermal energy at a higher rate relative to the stored thermal energy. This distinction in comparison to $\mathrm{Zn}$ atoms results in separation of regions consisting of $\mathrm{Cu}$ and $\mathrm{Zn}$ within the film at high annealing temperature of $900^{\circ} \mathrm{C}$.

\subsection{Optical properties}

Figure $6 \mathrm{a}$ and $\mathrm{b}$ illustrates the PL spectra and Lorentz fitting of PL spectra for as-deposited and post-annealed thin films, respectively. For as-deposited thin film, two strong emission peaks located at 432 and $460 \mathrm{~nm}$ (blue emission) are observed (figure 6b). After the annealing process at $300^{\circ} \mathrm{C}$, two peaks are noticed at about 410 and $530 \mathrm{~nm}$. These two peaks relate to violet and green emissions, respectively, and have very low intensities. At annealing temperatures 600 and $900^{\circ} \mathrm{C}$, another peak located at about $390 \mathrm{~nm}$ appeared (figure 6b), which related to UV emission. The intensity of these emission peaks increased with increase in the annealing temperatures (figure 6a). The PL spectra of $\mathrm{ZnO}$ has emission peak within the UV spectral region (360-400 nm). ${ }^{23}$ The absence of this peak in the PL of the as-deposited and annealed at $300^{\circ} \mathrm{C}$ films is due to the $\mathrm{Zn}-\mathrm{Al}-\mathrm{Cu}-\mathrm{O}$ composites, which did 


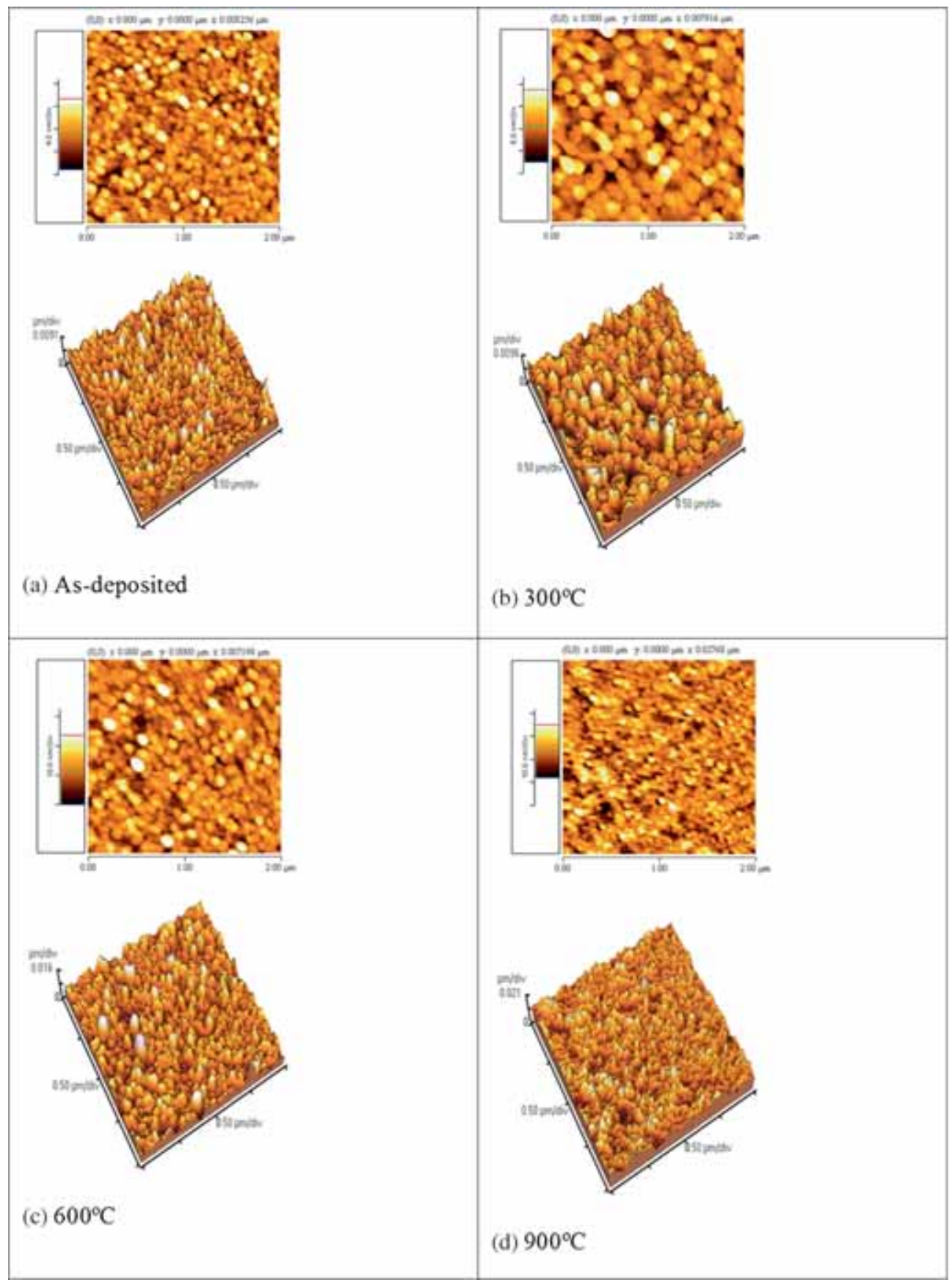

Figure 2. 2D and 3D of AFM images of CAZO nanocomposite thin films annealed at different temperatures: (a) as-deposited CAZO, (b) $300^{\circ} \mathrm{C}$ annealed CAZO, (c) $600^{\circ} \mathrm{C}$ annealed CAZO and (d) $900^{\circ} \mathrm{C}$ annealed CAZO.

not completely penetrate $\mathrm{Zn}, \mathrm{Cu}$ and $\mathrm{Al}$ atoms into each other and indicates lack of $\mathrm{ZnO}$ characterized structure. By annealing at $300^{\circ} \mathrm{C}$, the intensity of the peaks located at 432 and $460 \mathrm{~nm}$ decreases and two other peaks at 410, 390 and also a green spectral peak located at about $530 \mathrm{~nm}$ appear. This was considered as a result of making $\mathrm{ZnO}$ characterized structure and promotion of $\mathrm{Al}$ and $\mathrm{Cu}$ atoms diffusion into $\mathrm{ZnO}$ structure of thin film during annealing. The intensity of all these peaks is an increasing function of the annealing temperature.
It is well known that there are different defects like oxygen vacancies, zinc vacancies, interstitial oxygen, interstitial zinc and so on within the sputtered $\mathrm{ZnO}$ thin films. ${ }^{24}$ The band energy diagram is plotted in figure 7 to explain the energy band for PL spectra accordingly. Kang et $a l^{25}$ found that a $530 \mathrm{~nm}$ green emission peak in $\mathrm{ZnO}$ thin film is due to the transition from deep donor level by oxygen vacancies in $\mathrm{ZnO}$ to valence band. ${ }^{25}$ The green emission is due to the impurity of $\mathrm{Cu}^{2+}$ and $\mathrm{Cu}^{+}$ions, which replace zinc in $\mathrm{ZnO}$ structure. ${ }^{26}$ 


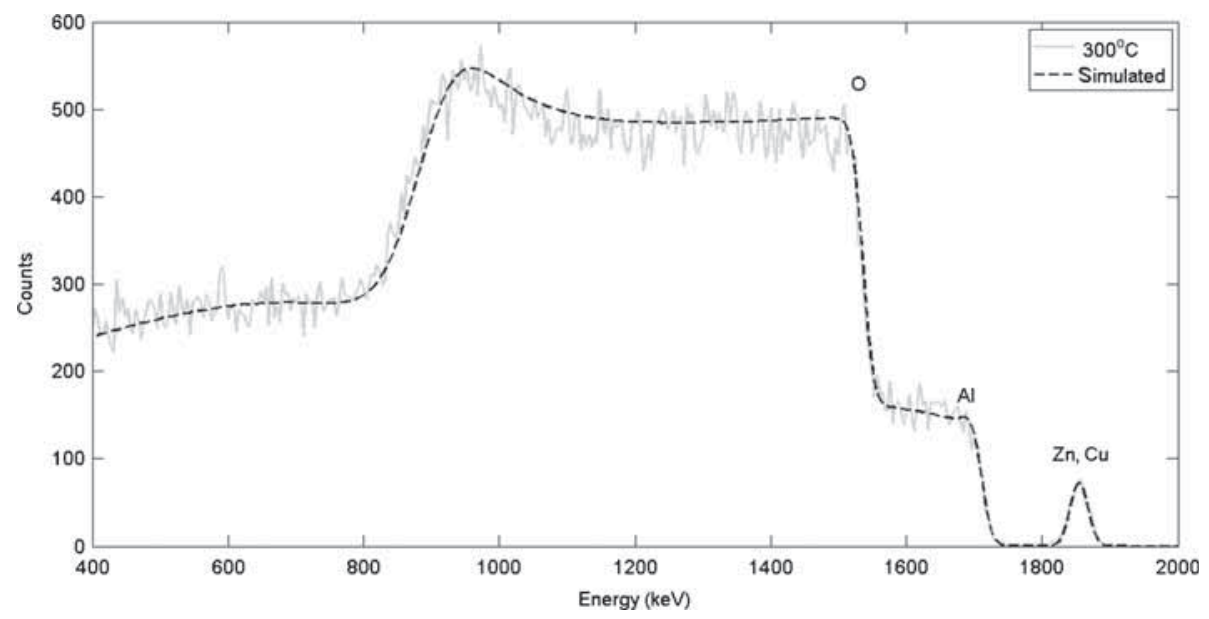

Figure 3. Atypical RBS spectrum of ACZO film prepared at $300^{\circ} \mathrm{C}$ with corresponding simulation curve.

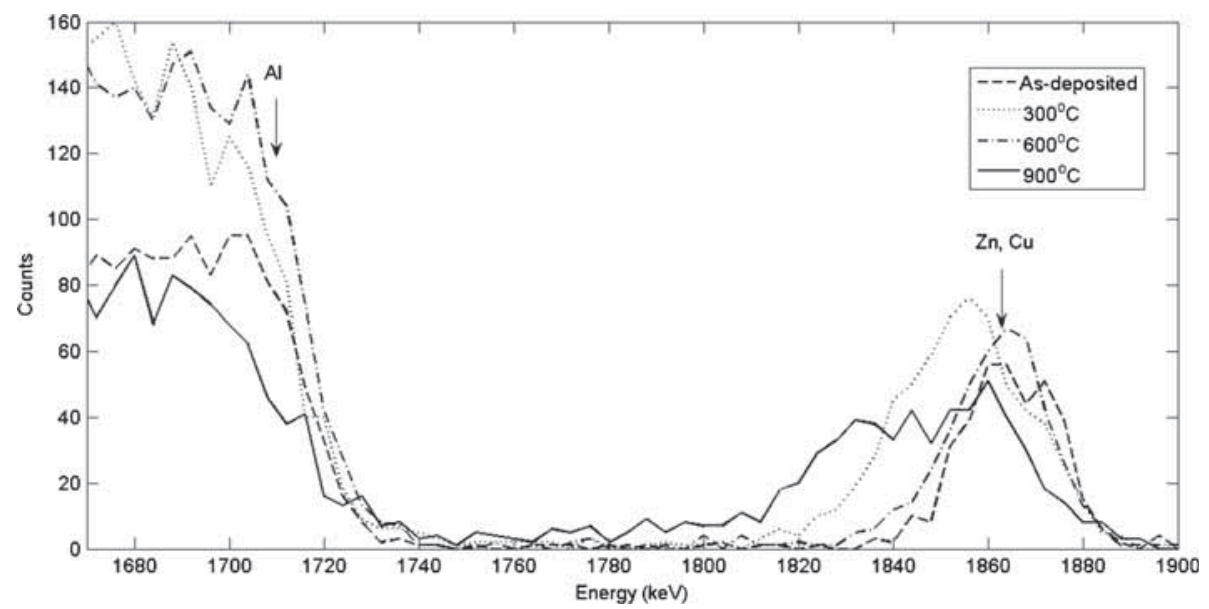

Figure 4. RBS spectra of CAZO nanocomposite films deposited at different temperatures on quartz substrate from 1650 to $1900 \mathrm{keV}$.

Violet emission is attributed to the transition from the conduction band to the deep hole trapped levels like $\mathrm{V}_{\mathrm{Zn}} \cdot{ }^{27} \mathrm{GaO}$ et $a l^{28}$ thought that the UV emission located at $391 \mathrm{~nm}$ originated from the electron transition from the localized levels below the conduction band to the valance band. According to $\mathrm{Xu}$ et $a l,{ }^{29}$ two 2.87 and $2.57 \mathrm{eV}$ blue emission peaks are related to the electron transition from both the interstitial $\mathrm{Zn}$ levels to valence band and the energy levels of interstitial $\mathrm{Zn}$ to $\mathrm{Zn}$ vacancies, and blue emission attributed to the transition from interstitial aluminium $\left(\mathrm{Al}_{\mathrm{i}}\right)$ levels to $\mathrm{Zn}$ vacancies, because $\mathrm{Al}$ atoms when substituted on the $\mathrm{Zn}$ site act as shallow donors in $\mathrm{ZnO} .^{19}$

After annealing at $300^{\circ} \mathrm{C}$ the intensity of the PL peaks are less pronounced and show a blue shift with respect to the asdeposited films. On the other hand, by increasing the annealing temperature to 600 and $900^{\circ} \mathrm{C}$ the PL peaks become stronger and the blue shift is no longer observed. Ko et al ${ }^{30}$ report that the PL intensity is related to the density of optically active defect states, hence the behaviour of PL peaks as a function of annealing temperature could be explained by the changes during the thermal annealing treatment within the thin films. The XRD of the CAZO films illustrate that annealing at $900^{\circ} \mathrm{C}$ causes a decrease in the grain size. The grain size variation affects the PL intensity, as the variation of the grain size could result in a decrease or an increase in the films adsorbing centres based on the formation of smaller or larger localized states.

Comparing the PL spectrum of nanocomposites of CAZO with $\mathrm{AZO}(\mathrm{Al}: \mathrm{ZnO})$ and $\mathrm{CZO}(\mathrm{Cu}: \mathrm{ZnO})$, as we described before the density of localized states increased in the visible region which is related to the defects and oxygen vacancies; ${ }^{18}$ therefore results in enhanced sensitivity and fast gas detection and responsively further indicating that nanocomposites of CAZO thin film is a good candidate for improving the sensing properties of gas sensor applications and technology.

The optical constants play an important role in optoelectronic devices. The spectral distribution of transmittance and reflectance for as-deposited and annealed CAZO thin films 


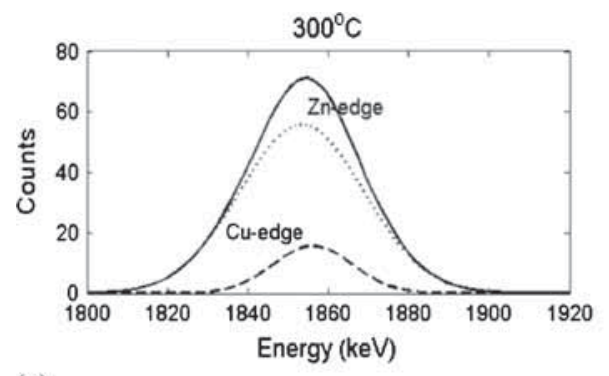

(a)

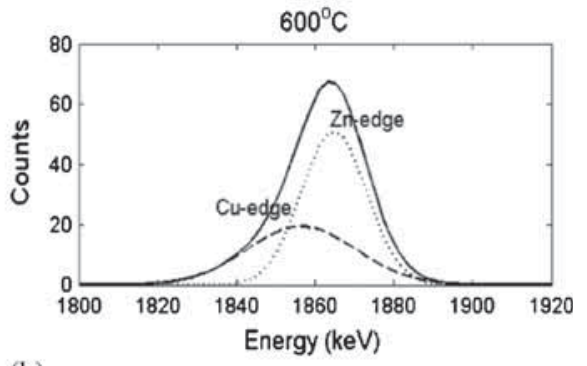

(b)

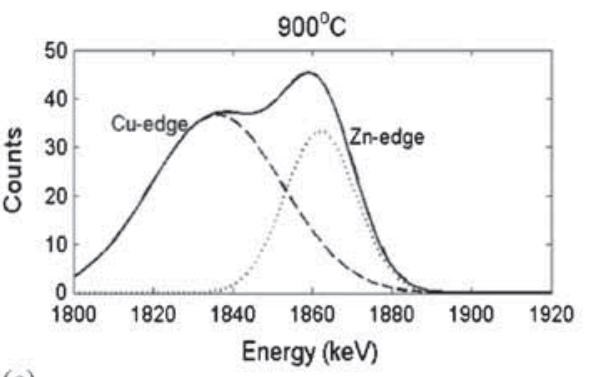

(c)

Figure 5. Deconvolution of the $\mathrm{Cu}$ and $\mathrm{Zn}$ edge from 1800 to $1900 \mathrm{keV}$ with two Gaussian fits of CAZO nanocomposite films deposited at different temperatures: (a) $300^{\circ} \mathrm{C}$ annealed $\mathrm{CAZO}$, (b) $600^{\circ} \mathrm{C}$ annealed $\mathrm{CAZO}$ and (c) $900^{\circ} \mathrm{C}$ annealed CAZO.

in the wavelength range of $200-1500 \mathrm{~nm}$ are illustrated in figure $8 \mathrm{a}$ and $\mathrm{b}$. The as-deposited film is opaque in the visible region (figure 8a), which is probably due to the strong absorption and scattering of the incident light by amorphous structure of the CAZO thin film. ${ }^{31}$

It is evident that the optical transmittance increases sharply in the visible and $\mathrm{UV}$ region with annealing at $900^{\circ} \mathrm{C}$. Therefore, thermal annealing in air could improve the optical transmittance of CAZO film by reacting with oxygen. ${ }^{32}$ Although the structure of films when annealed at 300 and $600^{\circ} \mathrm{C}$ did not show any distinguishable changes, but when annealed at $900^{\circ} \mathrm{C}$, the transmittance increased sharply due to improved crystal structure. This confirms the formation of $\mathrm{ZnO}$ or $\mathrm{ZnO}$ with $\mathrm{Al}$ and $\mathrm{Cu}$ impurities, which are transparent. ${ }^{33,34}$

According to the observations from prepared samples as-deposited and annealed to $\left(600^{\circ} \mathrm{C}\right)$ samples have dark appearance which was probably due to the strong absorption and scattering of the amorphous and low crystallinity structure. ${ }^{35}$ While annealed sample at $900^{\circ} \mathrm{C}$ has a light face and the transmittance of the film increased nearly $80 \%$. This noticeable increase of transmittance was due to the decrease in defects density, which was investigated after calculating $E_{\mathrm{u}}$ (equation 2).

The spectral behaviour of the reflectance $R(\lambda)$ in figure $8 \mathrm{~b}$ shows an annealing temperature dependence which is not regular, especially in the wavelength region $200<\lambda<400 \mathrm{~nm}$. With increasing annealing temperature to $600^{\circ} \mathrm{C}$ reflectance increases with increasing wavelength, but at annealing temperature higher than $600^{\circ} \mathrm{C}$ the reflectance decreases.

In our case, according to AFM results, the film surfaces remain nearly smooth at different temperatures indicating an insignificant role of roughness in reflectance variation. The variation of reflectance and transmittance spectrum of the sample annealed at $900^{\circ} \mathrm{C}$ could be related to improvement of crystallization within CAZO nanocomposites because the light scattering was decreased due to decrease in defects of the film.

In order to calculate the optical bandgap energy $\left(E_{\mathrm{g}}\right)$ of the thin films, we assume the absorption coefficient relation of $\alpha=(1 / d) \ln \left[\left(1-R^{2}\right) / 2 T\right]$, where $T$ and $R$ are the transmittance and reflectance, respectively, and $d$ the film thickness. ${ }^{36}$ The optical bandgap of samples was obtained by the following relation: ${ }^{34}$

$$
\alpha=\left(\frac{\mathrm{A}}{h v}\right)\left(h v-E_{\mathrm{g}}\right)^{m}
$$

Here, A is a constant that depends on the type of transition, $\mathrm{h} v$ is the photon energy and the type of transition can be obtained by finding the proper value of $m$. For determination of interband transition in films, figures of $(\alpha h v)^{m} v s$. photon energy h $v$ were plotted for $m=1 / 2,2,3 / 2,3$, where the best fit was obtained for $m=1 / 2$ and 2 , which are due to the allowed direct and indirect transitions, respectively. Figure 9 illustrates the plot of $(\alpha h v)^{2} v s$. the photon energy hv for as-deposited and annealed thin films. The straight line portion of the curve, when extrapolated to zero, gives the optical bandgap $E_{\mathrm{g}}$. The interband transition of CAZO thin films shows direct transition like $\mathrm{AZO}^{37}$ and $\mathrm{CZO}^{12}$ thin films.

The absorption at the lower photon energy usually follows the Urbach's rule ${ }^{33}$ according to the following equation

$$
\alpha(\lambda)=\alpha_{\mathrm{o}} \exp \left(\frac{h v}{E_{\mathrm{u}}}\right)
$$




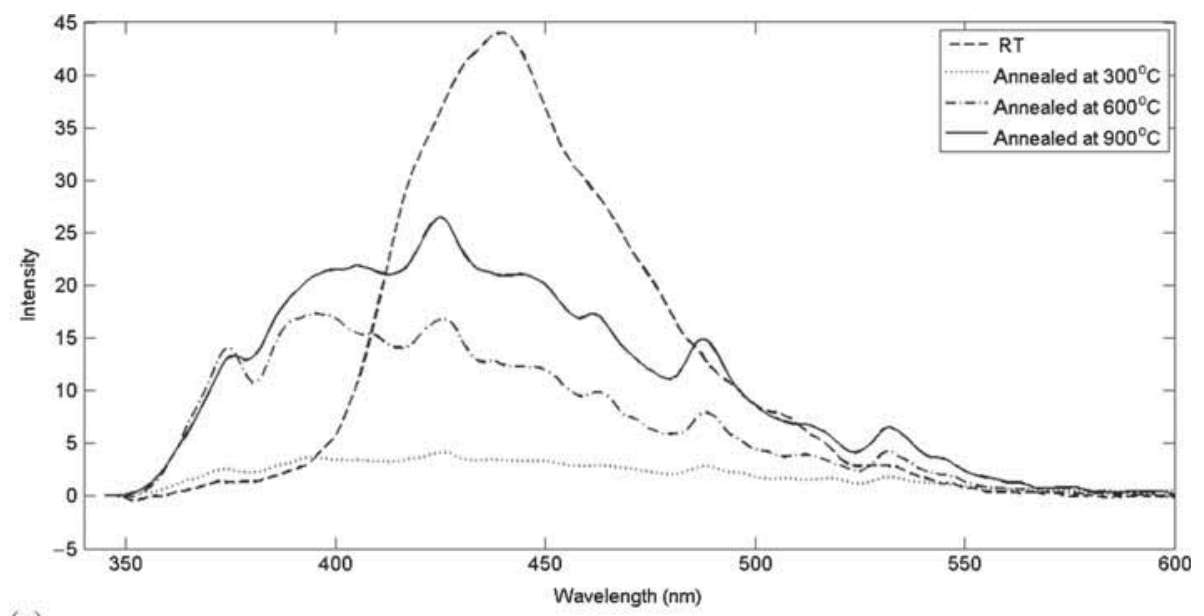

(a)
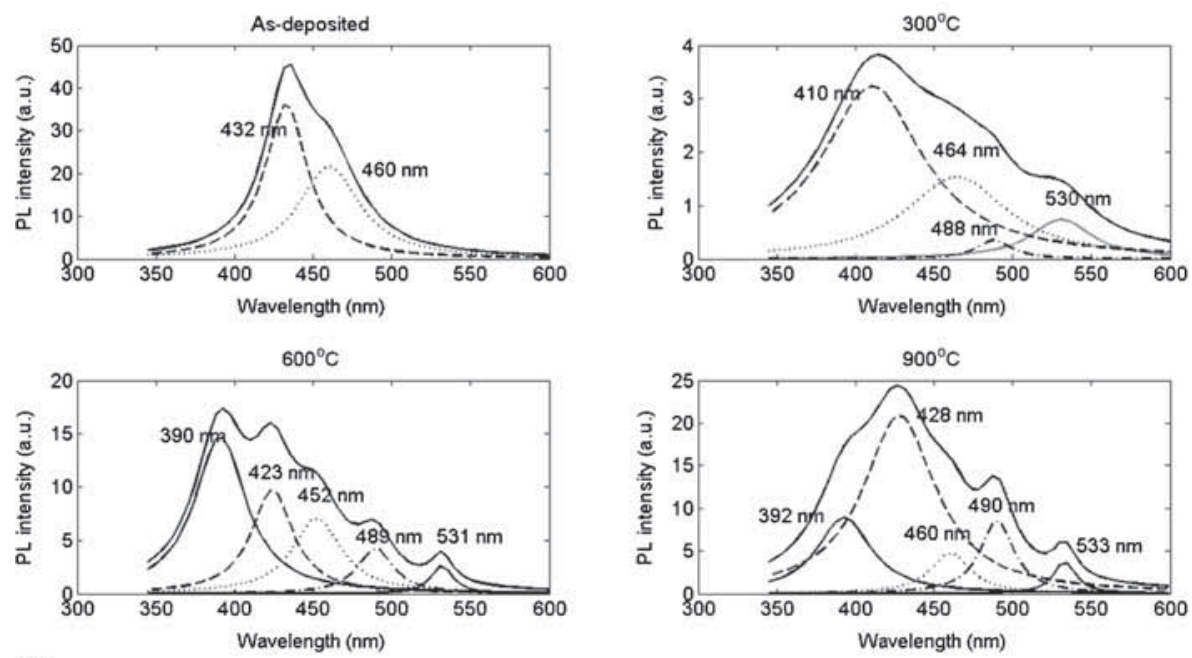

(b)

Figure 6. (a) PL spectra of CAZO nanocomposite thin films and (b) Lorentz fitting of the PL spectra at different temperatures.

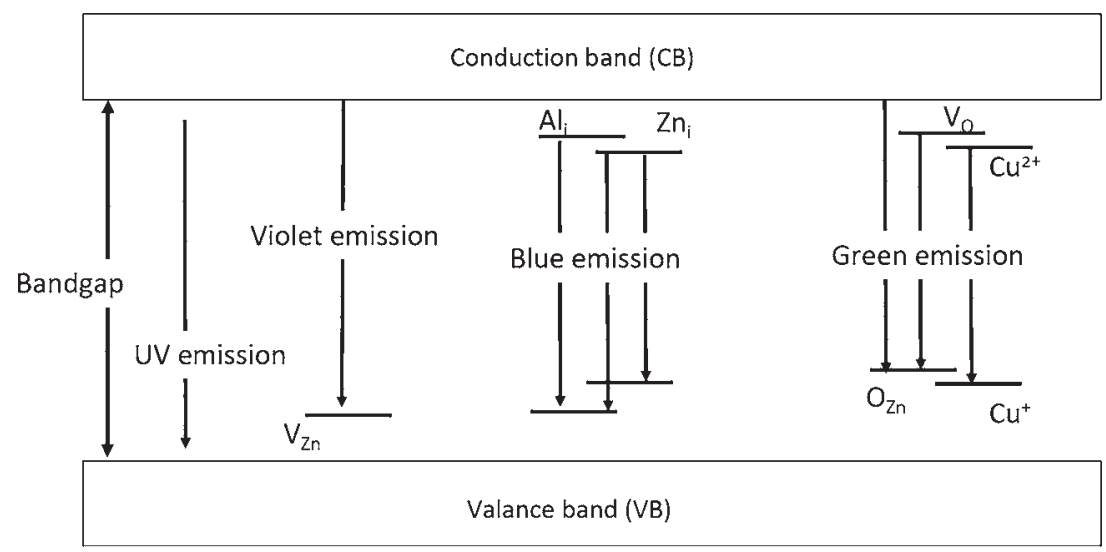

Figure 7. Schematic view of the energy band diagram proposed for CAZO nanocomposites.

where $v$ is the frequency of the radiation, $\alpha$ a constant, $h$ the Planck's constant and $E_{\mathrm{u}}$ is Urbach's energy which is interpreted as the width of the tails of localized states in the bandgap and in general represents the degree of disorder in amorphous semiconductors. ${ }^{38}$ The absorption in this region is due to the transitions between extended states in one band 


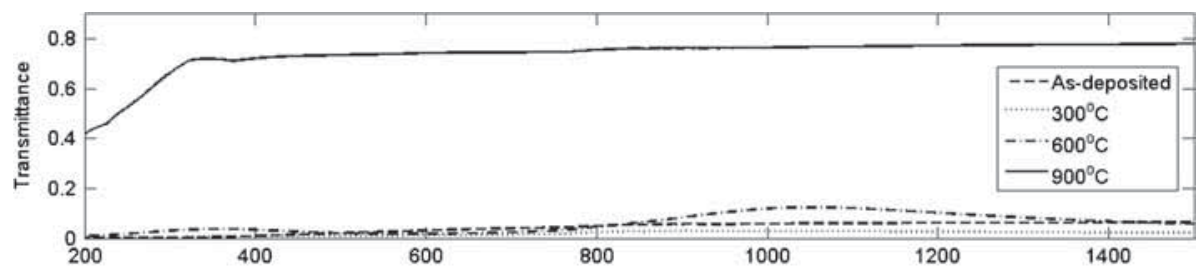

(a)

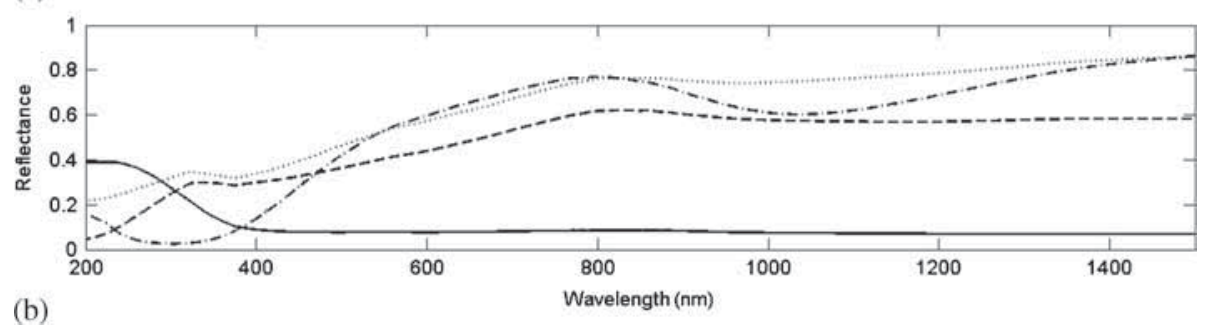

Figure 8. (a) Transmittance and (b) reflectance for as-deposited and annealed CAZO nanocomposites prepared at $300-900^{\circ} \mathrm{C}$.

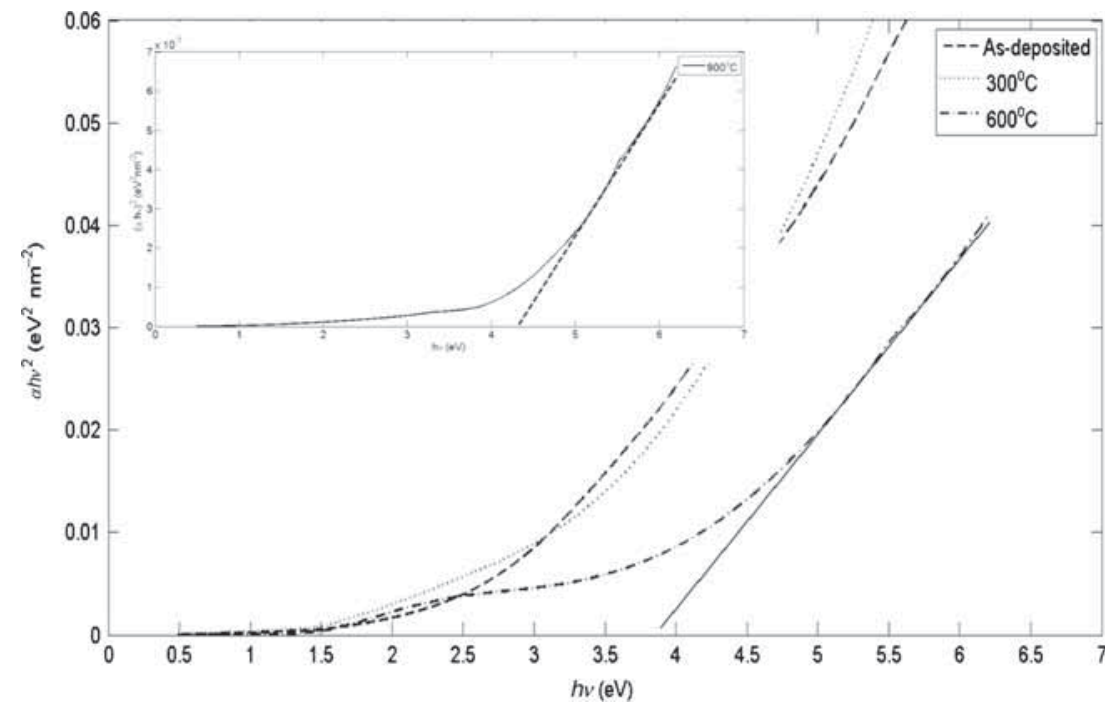

Figure 9. The plots of $(\alpha h v)^{2} v s$. photon energy of the CAZO nanocomposite thin films for as-deposited and annealed at 300 and $600^{\circ} \mathrm{C}$; inset: the plots of $(\alpha h v)^{2} v s$. photon energy of the CAZO nanocomposite thin films annealed at $900^{\circ} \mathrm{C}$.

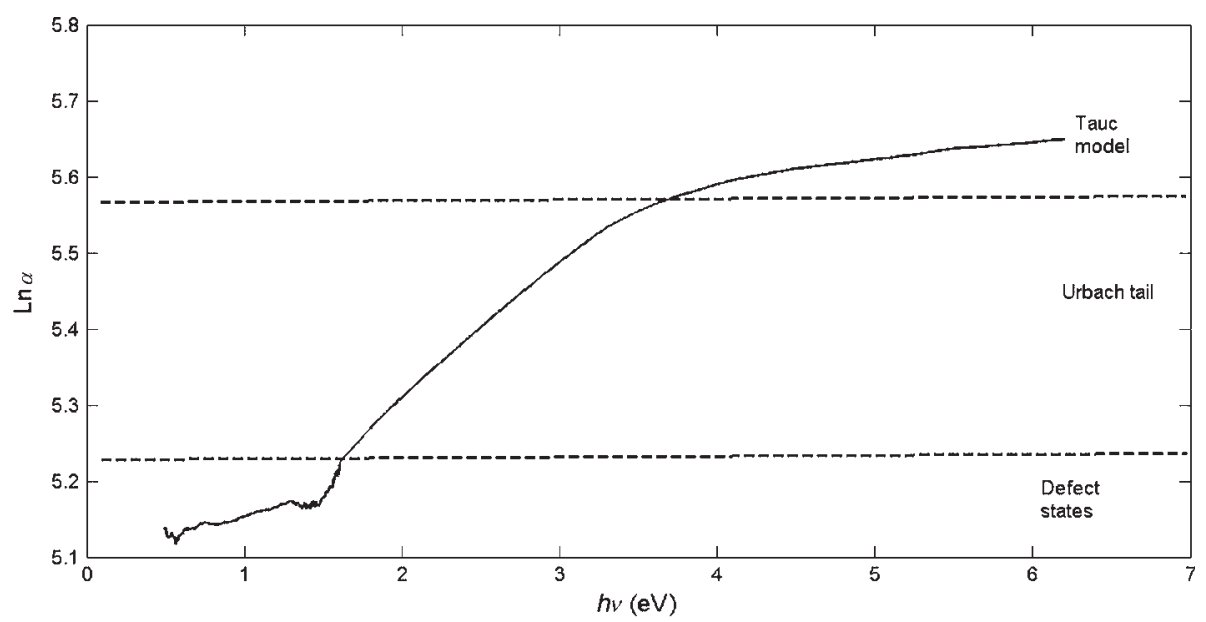

Figure 10. The plot of $\operatorname{Ln} \alpha v s$. photon energy for as-deposited of the CAZO nanocomposite thin films. 


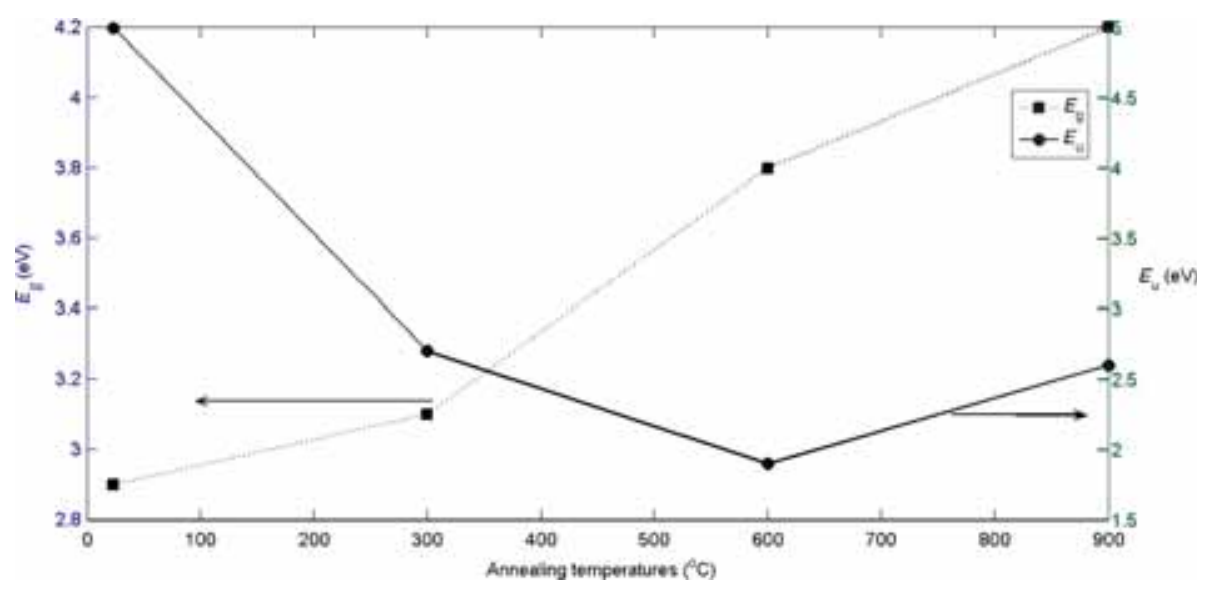

Figure 11. Effect of annealing on the $E_{\mathrm{g}}$ and $E_{\mathrm{u}}$ of CAZO films.

and localized states in the exponential tail of the other band. Figure 10 shows the plot of $\operatorname{Ln} \alpha$ as a function of $h v$ for the as-deposited film, in which the slope of straight line represents $E_{\mathrm{u}}$. This process has been applied to other samples for obtaining their $E_{\mathrm{u}}$. The obtained values of $E_{\mathrm{g}}$ and $E_{\mathrm{u}}$ are illustrated in figure 11. By increasing annealing temperatures in ambient air the optical bandgap of CAZO nanocomposites increase due to the increased diffusion of oxygen atoms in the thin films. The wide bandgap energy could also be due to the existence of $\mathrm{Al}$ and $\mathrm{Cu}$ impurities in the $\mathrm{ZnO}$ structure, which causes the formation of new recombination centres with higher emission energy, confirmed by the PL spectra. On the other hand, with increasing annealing temperatures to $600^{\circ} \mathrm{C}$ the Urbach energy of films decreases, but for films annealed at $900^{\circ} \mathrm{C}$ due to the formation of new crystalline phase it increases, indicating that the width of the localized tail states in the sample is increasing.

As it is reported in the literature the optical bandgap of $\mathrm{AZO}(\mathrm{Al}: \mathrm{ZnO})^{37}$ thin films decreases when the annealing temperature increases. On the other hand, the optical bandgap of $\mathrm{CZO}(\mathrm{Cu}: \mathrm{ZnO})$ is lower than the optical bandgap of $\mathrm{ZnO}(3.28 \mathrm{eV}){ }^{12}$ The optical bandgap of $\mathrm{CZO}$ is between 3.1 and $3.3 \mathrm{eV}$. Our results show that by adding both $\mathrm{Cu}$ and $\mathrm{Al}$ in $\mathrm{ZnO}$ and performing post-annealing treatment, the optical bandgap varies in the range of 2.9 to $4.2 \mathrm{eV}$.

\section{Conclusions}

In this paper, CAZO nanocomposited thin films were prepared on quartz substrates by RF magnetron sputtering and then the films were post-annealed at $300-900^{\circ} \mathrm{C}$ in ambient environment. XRD pattern of films illustrated amorphous nature for the as-deposited film and weak crystallization for the annealed films. RBS confirmed the existence of $\mathrm{Al}, \mathrm{Cu}$ and $\mathrm{Zn}$ elements in all films. Particle size and RMS roughness of CAZO nanocomposited thin films indicated a weak dependence on annealing temperatures and the particle size became more homogenized with increasing annealing temperatures. By increasing the annealing temperature from 300 to $900^{\circ} \mathrm{C}$ the optical bandgap of nanocomposites of CAZO was increased from 3 to $4.2 \mathrm{eV}$, which was found to be due to the increased presence of oxygen atoms within the thin film structures. On the other hand, with increasing annealing temperature Urbach energy of films decreased. This meant that the width of the localized tail states in the samples decreased. The analysis of PL spectra showed that the density of localized states increased in the visible region (green and blue emissions) by annealing of films when comparing PL spectrum of nanocomposites of CAZO with that of AZO $(\mathrm{Al}: \mathrm{ZnO})$ and $\mathrm{CZO}(\mathrm{Cu}: \mathrm{ZnO})$ films. The presence of these states could bring about increased sensitivity for highspeed gassensing applications. Therefore we predict that the nanocomposite of CAZO thin film could be a good composite candidate for improving the sensing properties because of the increased localized states and defects within its thin film structure.

\section{References}

1. Grundmann M, Frenzel H, Lajn A, Lorenz M, Schein F and Wenckstern H 2010 Phys. Status Solidi A 2071437

2. Stach S, Garczyk Ż, Ţălu Ş, Solaymani S, Ghaderi A, Moradian R, Nezafat Negin B, Elahi S M and Gholamali H 2015 J. Phys. Chem. C doi: 10.1021/acs.jpcc.5b04676

3. Pal U, Garcia-Serrano J, Casarrubias-Segura G, Koshizaki N, Sasaki and Terahuchi S 2004 Sol. Energ. Mat. Sol. C 81339

4. Ghaderi A, Elahi S M, Solaymani S, Naseri M, Ahmadirad M, Bahrami S and Khalili A E 2011 J. Phys. 771

5. He S H, Yang W, Liu C, Sun L W and Ye Z Z 2011 J. Phys. Chem. C 11558

6. Felbier P, Yang J, Theis J, Liptak R W, Wagner A, Lorke A, Bacher G and Kortshagen U 2014 Adv. Funct. Mater. 241988

7. Park H, Iftiquar $\mathrm{S} \mathrm{M}$, Trinh $\mathrm{T} T$, Jang J, Ahn S, Kim S, Lee J, Jung J, Shin C, Kim M and Yi J S 2014 J. Nanosci. Nanotechnol. 147710

8. Morales-Acosta M D, Quevedo-Lopez M A and Ramirez-Bon R 2014 Mater. Chem. Phys. 146380

9. Sharma A, Kumar S, Budhiraja N, Singh R and Singh M 2013 Adv. Appl. Sci. Res. 4252 
10. Ghijsen J, Tjeng L H, Van Elp J, Eskes H, Westerink J and Sawatzky G A 1988 Phys. Rev. B 38322

11. Lin J P and Wu J M 2008 Appl. Phys. Lett. 92134103

12. Ţălu Ş, Stach S, Ghodselahi T, Ghaderi A, Solaymani S, Boochani A and Garczyk Ż 2015 J. Phys. Chem. B 119 5662

13. Lu J G et al 2006 J. Appl. Phys. 100073714

14. Solaymani S, Ghaderi A and Nezafat N B 2012 J. Fusion Energy 31591

15. Koshizaki N, Yazumoto K, Terauchi S, Umehara H, Sasaki T and Oyama T 1997 Nanostruct. Mater. 9587

16. Garcia-Serrano J and Pal U 2003 Int. J. Hydrogen Energy 28 637

17. Dhara S and Giri P K 2011 Funct. Mater. Lett. 425

18. Chow L et al 2013 Sens. Actuators A 189399

19. Chen H X, Ding J J, Zhao X G and Ma S Y 2010 Physica B 4051339

20. Bolt P H, Habraken P M and Geus J W 1998 J. Solid State Chem. 13559

21. Wang J, Zhang L, Zhang X, Shen Y and Liu C 2013 J. Alloys Compd. 549231

22. Brown A I and Marco S M Introduction to heat transfer 3rd ed. (New York: McGraw-Hill) 1958

23. Gondal M A, Drmosh Q A, Yamani Z H and Saleh T A 2009 Appl. Surf. Sci. 256298
24. Tao Y M et al 2011 Vacuum $\mathbf{8 5} 744$

25. Kang H S, Kang J S, Kim J W and Lee S Y 2004 J. Appl. Phys. 951246

26. Ya I, Alivov M, Chukichev V and Nikitenko V A 2004 Semiconductors 3831

27. Dorranian D, Solati E and Dejam L 2012 Appl. Phys. A 109 307-314

28. Gao X D, Li X M and Yu W D 2004 J. Solid State Chem. 177 3830-3834

29. Xu P S, Sun Y M, Shi C S, Xu F Q and Pan H B 2003 Nucl. Instrum. Methods Phys. Res. B 199286

30. Ko C et al 2006 J. Korean Phys. Soc. 481277

31. Zhang Y et al 2013 J. Phys. Chem. Solids 741672

32. Xue S W et al 2008 J. Alloys Compd. 44821

33. Wang T, Liu Y, Fang Q, Wu M, Sun X and Lu F 2011 Appl. Surf. Sci. 2572341

34. Yahia I S, Farag A M, Cavas M and Yakuphanoglu F 2013 Superlattices Microstruct. $\mathbf{5 3} 63$

35. Reddy A S, Reddy P S, Uthanna S and Rao G M 2006 J. Mater. Sci.: Mater. Electron. 17615

36. Fox M 2001 Optical properties of solids (Oxford University Press)

37. Sui C, Lu Z and Xu T 2013 Opt. Mater. 352649

38. Tauc J 1974 Amorphous and liquid semiconductors (Plenum Press) 